\title{
Community Newsletter: Conversation analysis, relationship between autism and intellectual disability
}

\section{BY CHELSEY B. COOMBS}

17 OCTOBER 2021

Hello, and welcome to the Community Newsletter! I'm your host, Chelsey B. Coombs, Spectrum 's engagement editor.

Our first Twitter thread this week comes from Kristen Bottema-Beutel, associate professor at Boston College in Massachusetts. Her new study in Autism looked to understand interactions between autistic children and their caregivers by using 'conversation analysis.'

Our article on interactions $\mathrm{b} / \mathrm{w}$ autistic children and their caregivers is out! W/ @ShanCLaPoint \& @soyoonkimkang.We used a qualitative method, conversation analysis (CA), to re-analyze a type of caregiver talk that we have analyzed quantitatively $1 / 12$ https://t.co/Thcoij4SDN

—Kristen Bottema-Beutel (@KristenBott) September 25, 2021

How caregivers talk to autistic children is important for the children's development, and many studies of how children learn language use follow-in directives, or speech from a caregiver that relates to what a child is doing in that moment. But interventions that prompt caregivers to engage in follow-in directives don't have lasting positive effects. Bottema-Beutel and her colleagues say conversation analysis, "a qualitative, micro-analytic research tradition that focuses on how social interactions are organized and made sense of by the people participating in them," could be more effective. 


\section{Spectrum | Autism Research News}

https://www.spectrumnews.org

$\mathrm{CA}$ requires examination of long stretches of interaction to determine how social conduct is made relevant, and how it shapes the interaction going forward. This contrasts with quant methods, where talk is broken into discrete units. Using CA we found 'follow-in directives' $3 / 12$

— Kristen Bottema-Beutel (@KristenBott) September 25, 2021

The researchers applied conversation analysis to videos of caregivers and autistic children playing. When a caregiver issues a directive, such as "Now you try," she gives the child an opportunity to interact and respond more easily than if she hadn't, the team found.

"We argue that analyzing proposals in this way offers nuance to prior research on caregiver's use of follow-in directives, in ways that may be consequential for supporting parents in interacting with their autistic children who are in the early phases of language learning," the researchers write.

We hope this kind of work can shed light on the ways caregivers and their autistic children work together to build interactions, and the ways autistic children demonstrate their interactional abilities. 12/12

—Kristen Bottema-Beutel (@KristenBott) September 25, 2021

Sue Fletcher-Watson, professor of developmental psychology at the University of Edinburgh in Scotland, tweeted praise.

this is a v cool method! https://t.co/ENe07ztO1q

—Sue Fletcher-Watson (@SueReviews) September 25, 2021

Linda Watson, professor of speech and hearing sciences at the University of North Carolina at Chapel Hill, tweeted that during her doctoral studies, she found similar evidence. 
Different methods but similarities in the interpretation. We presented the findings at the first Annual BU Conference on Language Development. The 46th is this November. \#bucld

_-Dr. Linda Watson (@lindaritcwatson) September 26, 2021

Also this week on Twitter, Jonathan Sebat, professor of psychiatry and cellular and molecular medicine at the University of California, San Diego, threaded an ongoing debate: Is there one autism, with a spectrum of traits, or multiple autisms that can be categorized by different phenotypes? Sebat questioned the existence of autism without intellectual disability, a "holy grail" that some researchers seek, saying that autism with and without intellectual disability exist on the same spectrum.

During the autism session this morning I posed the question "If IQ is correlated with core features of ASD, what is this holy grail that some seek of 'autism without intellectual disability'? Couldn't this simply be the severe end of the same spectrum? $1 / n$ \#WCPG2021

— Jonathan Sebat (@sebatlab) October 12, 2021

Sebat hypothesizes that polygenic risk scores for autism, intelligence quotients and educational attainment all relate because of some intersecting subset of alleles for some highly regulated neurodevelopmental process.

Hypothesis: the intersection of PSasd and PSea is a subset of alleles that move the needle on some neurodevelopment process (who knows... synaptogenesis, cortical thickness etc...) that is tightly regulated in neurodevelopment. $5 / n$

— Jonathan Sebat (@sebatlab) October 12, 2021

Jacob Vorstman, associate professor of psychiatry at the University of Toronto in Canada, replied 


\section{Spectrum | Autism Research News}

https://www.spectrumnews.org

that autism "is not a necessary phenotype at the severe end of the IQ spectrum" because there are people who have intellectual disability but do not have autism.

One of the observations we need to account for is that we see individuals with ID, but without ASD. So ASD is not a necessary phenotype at the severe end of the IQ spectrum. Vice versa - we see individuals with ASD and with high IQ.

— Jacob Vorstman (@Jacob_Vorstman) October 12, 2021

Sebat responded that genetics currently suggests that autism without intellectual disability may be at the low-support end of the spectrum rather than a separate entity entirely.

Yes but people speak of "ASD without ID"... as if it's something fundamentally different. Is it? That's not what the genetics seems to suggest at the moment. It could simply be the milder end of the spectrum which would have less rare variant and PRS burden both

_ Jonathan Sebat (@sebatlab) October 12, 2021

Don't forget to register for our 28 October webinar, featuring Zachary J. Williams, a medical and doctoral student at Vanderbilt University in Nashville, Tennessee, who will speak about measuring alexithymia in autistic people and the importance of developing and validating measures for specific populations.

That's it for this week's Community Newsletter! If you have any suggestions for interesting social posts you saw in the autism research sphere, feel free to send an email to me at chelsey@spectrumnews.org. See you next week!

Cite this article: https://doi.org/10.53053/KXNS3616 